\title{
Mössbauer Spectroscopy of Iron Biomineralization Products in Magnetotactic Bacteria
}

\author{
RICHARD B. FRANKEL, GEORGIA C. PAPAEFTHYMIOU, and \\ RICHARD P. BLAKEMORE
}

\section{Introduction to Mössbauer Spectroscopy}

Mössbauer spectroscopy is a nuclear $\gamma$-ray resonance technique that has been extensively applied to the study of the electronic properties of iron in biological systems. The power of the technique lies in its sensilivity to the effects of the physical enviromment nature and disposition of ligands, magnetic structure, etc.) on ${ }^{57} \mathrm{Fe}$ nuclei. Moreover, it is sensitive only to ${ }^{57} \mathrm{Fe}$ so it is not affected by other elements in the system, except as they affect the environment of the iron atoms. The technique allows discrimination of nonequivalent iron sites as opposed to magnetic susceptibility or magnetization measurements which lump logether contributions from all the sources in the sample. As extensive reviews of Mossbater spectroscopy are available (Greenwood and Gibb, 1971: Bancroft, 1973: Cohen. 1976, 1981) we will only give a brief introduction here, focusing on ${ }^{57} \mathrm{Fe}$. This will be followed by a review of spectroscopy of iron in biomineralization products, and of magnetic inclusions in magnetotactic bacteria.

\subsection{Nuclear $\gamma$-Ray Absorption}

Nuclei have discrete energy levels tha! correspond to different configurations of the constituent protons and neutrons. Each energy level is characterized by a spin angular

RICHARD B. FRANKEL and GLORGIA C. PAPAEFTHYMIOU - Francis Bitter National Magnet Laboratory. Massachusetts Institute of Technology. Cambridge. Massachusetts 02139. RICHARD P. BLAKEMORE - Department of Microbiology Universily of New Hampshire, Durham. New Hampshire 03824. 


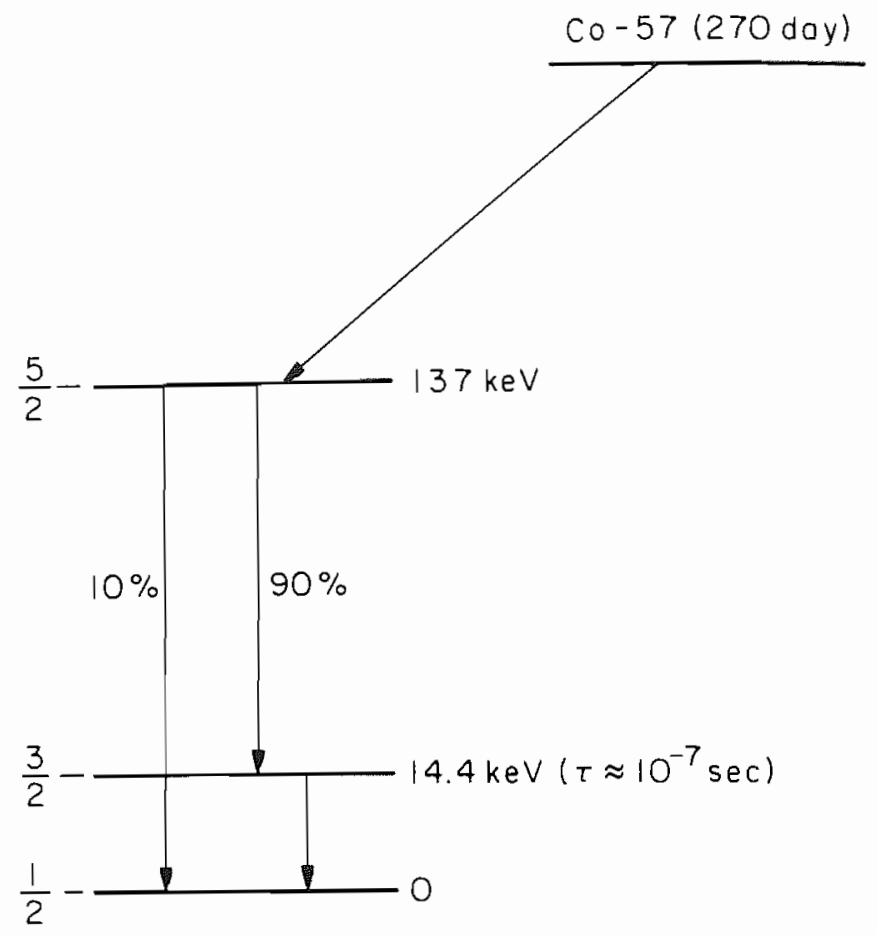

Figure 1. Decay scheme of ${ }^{57} \mathrm{Co}$ to ${ }^{57}$ lie.

momentum and other physical parameters. The low-lying energy levels of $2.2 \%$ abundant ${ }^{57} \mathrm{Fe}$ are shown in Fig. 1. The stable ground state has a spin $I_{0}=\underline{2}$ and there is an excited state at $\Delta \mathrm{E}=14.4 \mathrm{keV}$ with $\operatorname{spin} I_{14.4}=\frac{3}{2}$. An ${ }^{57} \mathrm{Fe}$ rucleus in the excited state, for example, following the decay of radioactive ${ }^{57} \mathrm{Co}$, can decay to the ground state by emitting a 14.4 $\mathrm{keV} \gamma$ ray (or by the alternative process of electron conversion), with a half-life of $\sim 10^{-7}$ sec. Conversely, a nucleus in the ground state can be excited to the $14.4-\mathrm{keV}$ state by absorption of a $\gamma$ ray with energy $E_{\gamma}=14.4 \mathrm{keV}$. The absorption probability or cross section is a function of $\gamma$-ray energy. It is a maximum at $\Delta E$ and falls to one-half its maximum value when $E_{\gamma}=\Delta E \pm \Gamma / 2$, where $\Gamma$ is the intrinsic linewidth of the $14.4-\mathrm{keV}$ excited state. The width is related to the lifetime of the state by the uncertainty principle:

$$
\Gamma=h / 2 \pi \tau
$$

where $h$ is Planck's constant. Because $\tau=10^{-7} \mathrm{sec}, \Gamma=5 \times 10^{-9} \mathrm{eV}$ for the $14.4-\mathrm{keV}$ state. Thus, $\Gamma / \Delta E=10^{-12}$ !

Because electromagnetic radiation has momentum, the nucleus must recoil when it absorbs the $\gamma$ ray in order to conserve linear momentum. Thus, some of the $\gamma$-ray energy goes into recoil energy and is not available for excitation. The momentum of the $\gamma$ ray $p$ $=E_{\gamma} / c$, hence the recoil energy

$$
R=\mathrm{p}^{2} / 2 M_{\mathrm{n}}=E_{\gamma}^{2} / 2 M_{\mathrm{n}} \mathrm{c}^{2}
$$

where $M_{n}$ is the mass of the nucleus and $c$ is the speed of light. For ${ }^{57} \mathrm{Fe}, R=0.002 \mathrm{eV}$, i.e., $R \geqslant \Gamma$. Because of nuclear recoil, the cross section for absorption will be low even when $E_{\gamma}$ is precisely equal to $\Delta E$. Mössbauer's great discovery was that if the nucleus is 
embedded in a solid, there is a certain probability that the recoil momentum will be taken up by the solid as a whole. In those cases, $R \rightarrow 0$ because $M_{n}$ in the denominator of Eq. (2) is replaced by the mass of the entire solid, i.e., of the order of $10^{23}$ times the mass of the single nucleus. Hence, the Mössbauer effect is recoilless nuclear $\gamma$-ray resonance.

The probability of recoilless absorption $f$ is a function of $M_{n}, E_{\gamma}$, and the vibrational characteristics of the solid. It is temperature dependent, decreasing with increasing temperature. These and various other considerations limit the number of isotopes in addition to ${ }^{57} \mathrm{Fe}$ for which resonant absorption can be observed.

The most convenient source of $14.4-\mathrm{keV} \gamma$ rays for Mössbauer spectroscopy of iron in a particular material is radioactive ${ }^{57} \mathrm{Co}$ which decays to ${ }^{57} \mathrm{Fe}$ with a half-life of 270 days. As in the case of $\gamma$-ray absorption, $\gamma$-ray emission also involves recoil momentum, but if the radicactive nuclei are embedded in a solid, recoilless emission can occur. In practice, ${ }^{57} \mathrm{Co}$, which is produced in a cyclotron, is usualiy electroplated and diffused into a metallic host such as $\mathrm{Cr}, \mathrm{Cu}, \mathrm{Rh}, \mathrm{Pd}$, or Pt.

In order to observe the resonance, it is necessary to vary the $\gamma$-ray energy by an amount of the order of several times $\Gamma$. This is accomplished by changing the effective frequency of the $\gamma$ ray through the Doppler effect by moving the source of $\gamma$ rays relative to the absorber. The change in energy

$$
\delta E=(V / c) E_{\gamma}
$$

where $v$ is the relative velocity. For ${ }^{57} \mathrm{Fe}, \delta E=2 \Gamma$ when $v=0.2 \mathrm{~mm} / \mathrm{sec}$ so velocities of the order of $1 \mathrm{~mm} / \mathrm{sec}$ to $1 \mathrm{~cm} / \mathrm{sec}$ are sufficient to sweep out the entire line.

The spectrum is most often observed by measuring the intensity of $\gamma$ rays transmitted through the absorbber as a function of relative velocity which is equivalent to energy [Eq. [3]]. At high positive or negative velocities, high transmission occurs because the $y$ rays have been Doppler shifted off resunance. At velocities close to zero, the absorption cross section is high and the transmitted intensity is relatively low. The experimental linewidth is at least $2 \Gamma^{\prime}$ because it includes the intrinsic widths of both the source and the absorber.

\subsection{Hyperfine Interactions}

The usefulness of Mössbauer spectroscopy for the study of iron in materials stems from the fact that interactions of the nucleus with the environment perturb the nuclear levels with consequent changes in the $\gamma$-ray absorption spectrum (Freeman and Frankel, 1967). These interactions are collectively known as hyperfine interactions because they result in energy shifts or splittings of the nuclear levels which are tiny compared to 14.4 $\mathrm{keV}$ but which are nevertheless comparable or larger than $\Gamma$.

The three most important interactions leading to spectral features include (1) the isomer shift, (2) the quadrupole splitting, and (3) the magnetic hyperfine splitting (Fig. 2). In general, these interactions result in nuclear-level energy changes or splittings and can be written as a product of nuclear and electronic factors. The nuclear factors are measured properties associated with each nuclear level. The electronic factors depend on electronic environment. Determination of the electronic factors gives information about the electron structure in the solid.

The isomer shift arises from the fact that the ground state and the 14.4-keV excited state have different mean-squared charge radii. Hence, the electrostatic interaction between the nuclear charge and the atomic electrons will be different for ground and excited states and the energy difference between the two states will be affected by the total electronic. charge density at the nucleus. This charge density is mostly due to the atomic s electrons and is affected by the chemical enviromment. Thus, the splitting between ground and 
SOURCE

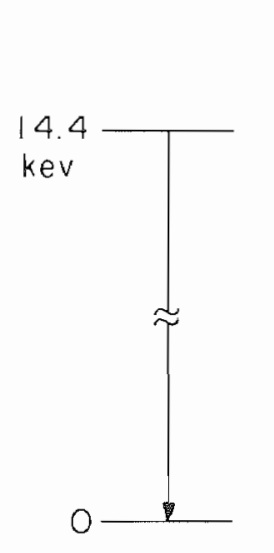

\section{ABSORBER}

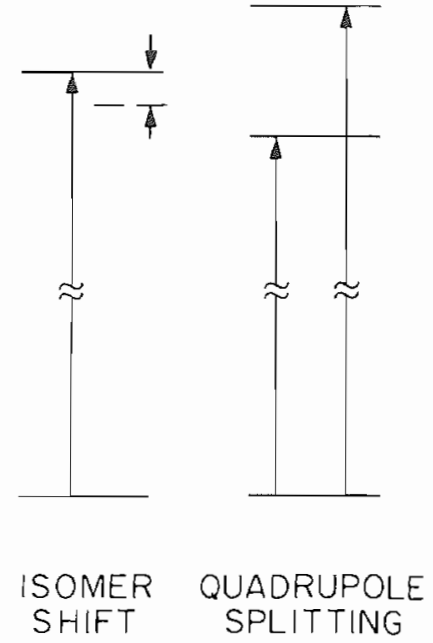

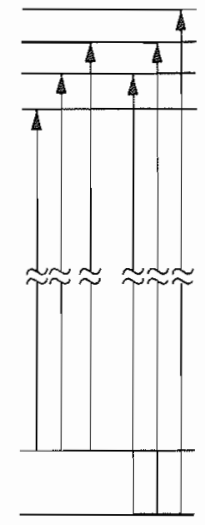

MAGNETIC SPLITTING

Figure 2. Effect of hyperfine interactions on the ${ }^{57} \mathrm{Fe}$ nucleus.

excited nuclear states will be different in different chemical environments, resulting in a relative shift of the centroid of the absorption line. If the $\gamma$-ray source is chemically different than the absorber, the absorption line will no longer be centered at $v=0$, but will be shifted to higher or lower velocities. Large differences in the s-electron density and consequently large isomer shifts occur for iron atoms in different oxidation states. The shit between $\mathrm{Fe}^{2+}$ and $\mathrm{Fe}^{3+}$ can be more than $1 \mathrm{~mm} / \mathrm{sec}$. Isomer shifts are generally quoted relative to iron metal.

A splitting of the 14.4-keV nuclear levels can result from the interaction of the nuclear quadrupole moment with an electric field gradient due to the electrons if the local symmetry about the iron atom is less than cubic. As the $14.4-\mathrm{keV}$ state has $\operatorname{spin} I=\frac{3}{2}$, it is 21 $+1=$ fourfold degenerate. The quadrupole interaction splits the states into two sublevels, each with twofold degeneracy. This results in an absorption spectrum with wo lines of equal intensity (for a polycrystalline absorber). The magnitude of the splitting $\lrcorner E_{Q}$ is a direct measure of the electric field gradient which depends on the local electronic environment and the orbital angular momentum. Fe ${ }^{3-}$ (high spin) has a half-filled $3 d$ shell and no orbital angular momentum and the quadrupole splittings are typically small, $\Delta E_{Q}$ $<1.0 \mathrm{~mm} / \mathrm{sec}$. $\mathrm{Fe}^{2+}$ can have unquenched orbital angular momentum and consequently large quadrupole splittings, $\Delta E_{\mathrm{Q}}>2.0 \mathrm{~mm} / \mathrm{sec}$, because of the extra electron outside of the half-filled shell.

A magnetic field acting on the nucleus completely raises the fourfold degeneracy of the $I=\frac{3}{2}$ excited state and the twofold degeneracy of the $I=\frac{1}{2}$ ground state. The splitting between the nuclear sublevels depends on the magnitude of the magnetic field at the nucleus and the magnetic moments of the ground and excited nuclear states. Although there are eight possible combinations of the four excited sublevels with the two ground sublevels, only six transitions are allowed and hence only six lines are usually observed in the Mössbauer spectrum [Fig. 3]. An effective magnetic field at the nucleus, the magnetic hyperfine field $H_{\mathrm{hf}}$, results from the interaction of the nuclear magnetic moment with the atomic magnetic moment. In high-spin $\mathrm{Fe}^{3+-}$ with five unpaired electrons, the magnitude of $\mathrm{H}_{\mathrm{ln}}$ is typically of the order of $500 \mathrm{kOe}$ and negative in sign, that is, the effective field due to the magnetic hyperfine interaction is oriented antiparallel to the atomic magnetic 


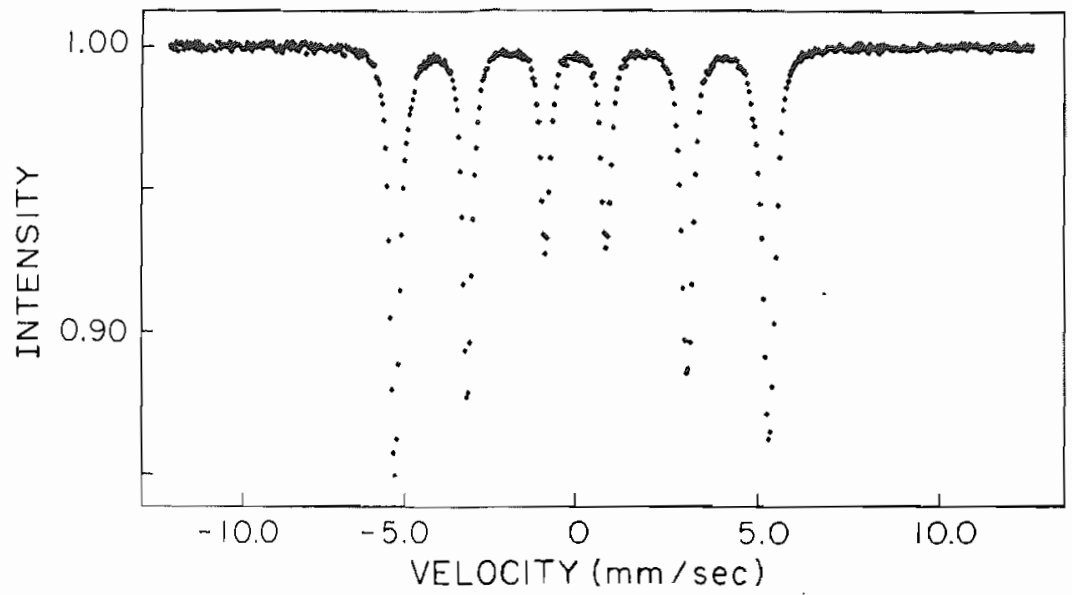

Figure 3. Mössbauer spectrum of iron metal at room temperature.

moment. In $\mathrm{Fe}^{2+}$ the atomic moments are typically smaller and more variable from compound to compound because of oroital contributions; this is reflected in smaller and more variable magnetic hyperfine fields. In iron metal where the moment per iron atom is 2.2 $\mu_{\mathbf{B}}$, the magnetic hyperfine field is $-330 \mathrm{kOe}$ (at room temperature).

The magnetic field causes the nucleus to precess with a frequency $\nu_{\mathrm{L}}$ that is proportional to the field strength; the time for a single complete precession is known as the Larmor precession time. For an $\mathrm{Fe}^{3+}$ atom with $\left|H_{\mathrm{hf}}\right|=500 \mathrm{kOe}$, this is about $10^{-7} \mathrm{sec}$. If the field fluctuates or changes sign ciue to relaxation of the atomic moment on a time scale less than the Larmor precession time, the magnetic splitting will not be observed and the Mössbauer spectrum will consist of a single line (or quadrupole doublet). This is generally the case for paramagnetic iron atoms. In ferro-, ferri-, or antiferromagnetic iron compounds where each atomic moment is oriented in a fixed crystallographic direction, the full magnetic splitting is ubserved in the spectrum. As the temperature increases through the Néel or Curie point (the magnetic ordering temperature) above which the material is paramagnetic, the spectrum splitting decreases and collapses to a single line (or quadrupole doublet), reflecting the transition from magnetic order to paramagnetism.

The magnetic splitting can also be observed in paramagnets when the electron spin is polarized by an external magnetic field. The magnetic hyperfine splitting depends on degree of polarization or magnetization of a paramagnet, which varies with $H_{0} / T$ up to its full or saturation vahue. However, in an external field, two additional factors come into play. First, the field at the nucleus $H_{11}$ is now the vector sum of the applied field $H_{0}$ and the magnetic hyperfine field $H_{12}$ :

$$
\mathrm{H}_{\mathrm{n}}=\mathrm{H}_{\mathrm{ni}}+\mathrm{H}_{0}
$$

In paramagnets where the atomic moment is polarized parallel to $H_{0}$, the equation reduces to a scalar equation and $H_{0}$ adds or subtracts from $H_{1, f}$. Because $H_{\text {hr }}$ is usually negative. the net field is the difference between $H_{\mathrm{li}}$ and $H_{0}$. For example, Fe ${ }^{3+}$ with $\left|H_{\mathrm{hi}}\right|=500$ kOe in a $60-k O e$ extemal field at low temperature would have a spectral splitting corresonding to $440 \mathrm{kOe}$. Second, the relative intensities of the spectral lines depend on the orientation of $H_{n}$ with respect to the $\gamma$-ray propagation direction. If the $\gamma$ rays are propagated parallel to the field direction, the relative intensities of the six lines are $3: 0: 1: 1: 0: 3$. If the $\gamma$ rays are propagated perpendicular to the field direction, the relative intensities are 
$3: 4: 1: 1: 4: 3$. In a polycrystalline, magnetically ordered material, the relative intensities average to $3: 2: 1: 1: 2: 3$.

If a magnetically ordered material is placed in an external magnetic field, similar effects occur (Chappert et al., 1979). In a ferromagnet, the magnetization is generally polarized parallel to $H_{0}$, in which case the field at the nucleus is the difference between $H_{h f}$ and $H_{0}$. The spectral intensities follow the same rules as outlined above. In a ferrimagnet, where there are two or more magnetic sublattices with antiparallel moment orientation, the net moment of the material will orient parallel to the applied field and the field will subtract from the hyperfine field of those atoms whose moments are oriented parallel to the net moment, but will add to the hyperfine fields of those atoms whose moments are oriented antiparallel to the net moment. In antiferromagnets, the moments of the two antiparallel sublattices cancel each other and there is no net moment to orient in the applied field. The applied field simply broadens the lines without changing their positions or relative intensities compared with zero field.

Superparamagnetism in small particles of magnetically ordered materials can be ob. served in the Mössbauer spectrum. In this phenomenon, thermal energy excites transitions of the magnetization, or of the sublattice magnetizations in antiferromagnets, between energetically equivalent crystaliographic axes. These transitions are opposed by energy barriers proportional to $K V$, where $K$ is the anisotropy energy per unit volume and $V$ is the volume of the particle. $K$ is a constant, characteristic of each magnetic material. The frequency of transition is given by

$$
f=f_{0} \exp \left[-K V / 2 k_{B} T\right]
$$

where $f_{0}$ is a constant and $k_{B}$ is Boltzmann's constant. Changes in the Mössbauer spectrum occur when $f=\nu_{\mathrm{L}}$, the Larmor precession frequency, as discussed above for paramagnets. For $\mathrm{Fe}^{3+}$ with a hyperfine field of $500 \mathrm{kOe}, \nu_{\mathrm{L}}=10^{7} \mathrm{sec}^{-1}$. According to Eq. (5), this condition will occur at a temperature $T_{B}$ for a given particle size. For $T<T_{B}$, one will observe the full magnetic splitting in the spectrum. For $T>T_{B}$, one will observe a collapsed or paramagnetic spectrum, i.e., a single line or quadrupole doublet. If there is a distribution of particle sizes in the sample, the condition $f=\nu_{\mathrm{L}}$ will be satisfied in different particles at different temperatures. Thus, there will be a region of temperature over which the sixline spectrum and the collapsed spectrum coexist, with the latter increasing in intensity and the former decreasing in intensity with increasing temperature. This is illustrated in the case of the iron storage protein ferritin discussed below. Note that the condition for observation of superparamagnetism by the Mössbauer effect is different than that for magnetization measurements. If $f=1 \mathrm{sec}^{-1}$, the remanent magnetization will decay rapidly but the particle will be stable on the Mössbauer time scale.

\subsection{Spectroscopy of Iron Oxides and Hydroxides}

Iron in a large number of compounds and minerals has been studied by Mössbauer spectroscopy. Iron oxides and hydroxides are particularly relevant to iron biomineralization processes so we will briefly review their spectral features here.

$\alpha-\mathrm{Fe}_{2} \mathrm{O}_{3}$, hematite, has a close-packed oxygen lattice with $\mathrm{Fe}^{3+}$ ions in octahedral sites. The magnetic ordering temperature is $950^{\circ} \mathrm{K}$. Up to about $250^{\circ} \mathrm{K}$, the magnetic ordering is antiferromagnetic. At $250^{\circ} \mathrm{K}$, the material undergoes a transition known as the Morin transition to a weakly ferromagnetic state in which the two sublattices cant toward each other producing a small net moment. The Mössbauer spectrum is a single six-line pattern with a magnetic splitting of $515 \mathrm{kOe}$ at room temperature (Fig. 4) and $540 \mathrm{kOe}$ at 


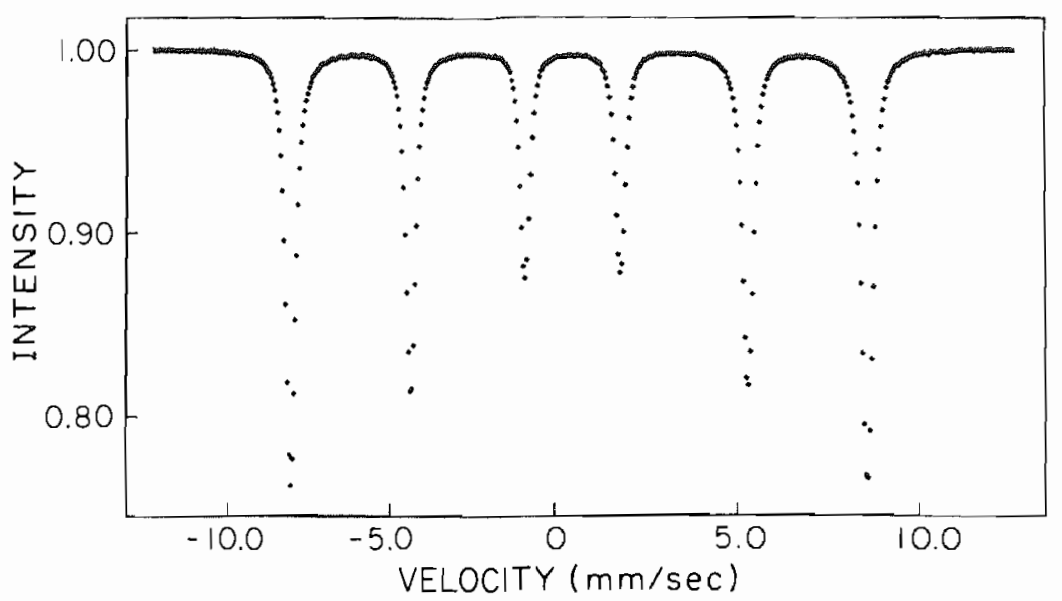

Figure 4. Mössbauer spectrum of $\alpha-\mathrm{Fe}_{2} \mathrm{O}_{3}$ at room temperature.

$4.2^{\circ} \mathrm{K}$. The spectrum undergoes subtle changes at the Morin transition (van der Woude, 1966).

$\gamma-\mathrm{Fe}_{2} \mathrm{O}_{3}$, maghemite, has a spinel $\left(\mathrm{xy}_{2} \mathrm{O}_{4}\right)$ structure in which $\mathrm{Fe}^{3+}$ ions in the $\mathrm{x}$ sites are tetrahedrally coordinated and $\mathrm{Fe}^{3+}$ ions in the $\mathrm{y}$ sites are octahedrally coordinated. Antiparaliel alignment of iron atoms in $x$ and $y$ sites results in a ferrimagnetic structure. The Mösbauer spectra of iron in the two sites are almost identical but they can be distinguished in an external magnetic field. The hyperfine fields are about 490 and $500 \mathrm{kOe}$ for the $x$ and $y$ sites, respectively, at room temperature (Armstrong et al., 1966).

$\mathrm{Fe}_{3} \mathrm{O}_{4}$, magnetite, has an inverse spinel structure $\left(\mathrm{xy}_{2} \mathrm{O}_{4}\right)$ in which $\mathrm{x}$ is $\mathrm{Fe}^{3+}$ in tetrahedrally coordinated sites and the two $y^{\prime}$ s are $\mathrm{Fe}^{2+}$ and $\mathrm{Fe}^{3+}$ in octahedrally coordinated sites. The magnetic structure is ferrimagnetic with the $\mathrm{Fe}^{2+}$ and $\mathrm{Fe}^{3+}$ in octahedral sites aligned parallel to each other and antiparallel to $\mathrm{Fe}^{3+}$ in tetrahedral sites. At room temperature, there are rapid electron transitions between iron atoms in the $y$ sites and the Mössbauer spectrum consists of two overlapping subspectra, one due to $\mathrm{Fe}^{3-}$ in $x$ sites, the other an averaged spectrum due to $\mathrm{Fe}^{2+}$ and $\mathrm{F} \mathrm{e}^{3+}$ in $\mathrm{y}$ sites (Fig. 5a). The latter spectrum las a smaller hyperfine splitting $\left(H_{\mathrm{hf}}=453 \mathrm{kOe}\right)$ and a positive isomer shift compared to the $x$-site spectrum $\left[H_{h t}=491 \mathrm{kOe}\right)$, reflecting the ferrous character of the $y$ sites. Below about $120^{\circ} \mathrm{K}$, the temperatures of the so-called Verwey transition, $\mathrm{Fe}_{3} \mathrm{O}$ : has a complex magnetic structure which results in two partially resolved subspectra, one with $H_{\mathrm{hi}}=500$ kOe, the other with $H_{\mathrm{h} f}=480 \mathrm{kOe}$ [Fig. 5b]. The former is due to $\mathrm{Fe}^{3+}$ in $\mathrm{x}$ and in $\mathrm{y}$ sites, which, like $\gamma$ - $\mathrm{Fe}_{2} \mathrm{O}_{3}$, have similar spectra. The latter subspectrum is due to $\mathrm{Fe}^{2+}$ in $y$ sites (Banerjee et al., 1967; Hargrove and Kundig, 1970).

Mössbauer studies of small particles of $\mathrm{Fe}_{3} \mathrm{O}_{4}$ have also been carried out. with observation of superparamagnetic effects (McNabb et al., 1968).

$\alpha-\mathrm{FeOOH}$, geothite, has $\mathrm{Fe}^{3+}$ atoms in distorted octahedral sites. The structure is antiferromagnetic below about $400^{\circ} \mathrm{K}$. The magnetic splitting of the Mössbauer spectrum at low temperature is about $500 \mathrm{kOe}$, which decreases to 380 at room temperature (Forsyth et al., 1968). $\mathrm{B}-\mathrm{FeOOH}$ also has $\mathrm{Fe}^{3+}$ in octahedral sites, but the structure is nonstoichiometric. The magnetic ordering is antiferromagnetic below $295^{\circ} \mathrm{K}$ and the magnetic splitting of the Mössbauer spectrum is $475 \mathrm{kOe}$ at low temperature (Dezsi et al., 1967). $\gamma-\mathrm{FeOOH}$, lepidocrocite, is similar to $\beta-\mathrm{FeOOH}$, but with a complex laver structure. It is paramagnetic to below $77^{\circ} \mathrm{K}$ where it becomes antiferromagnetically ordered. However, the Néel temperature is not well defined and magnetically split and collapsed spectra coexist over about 


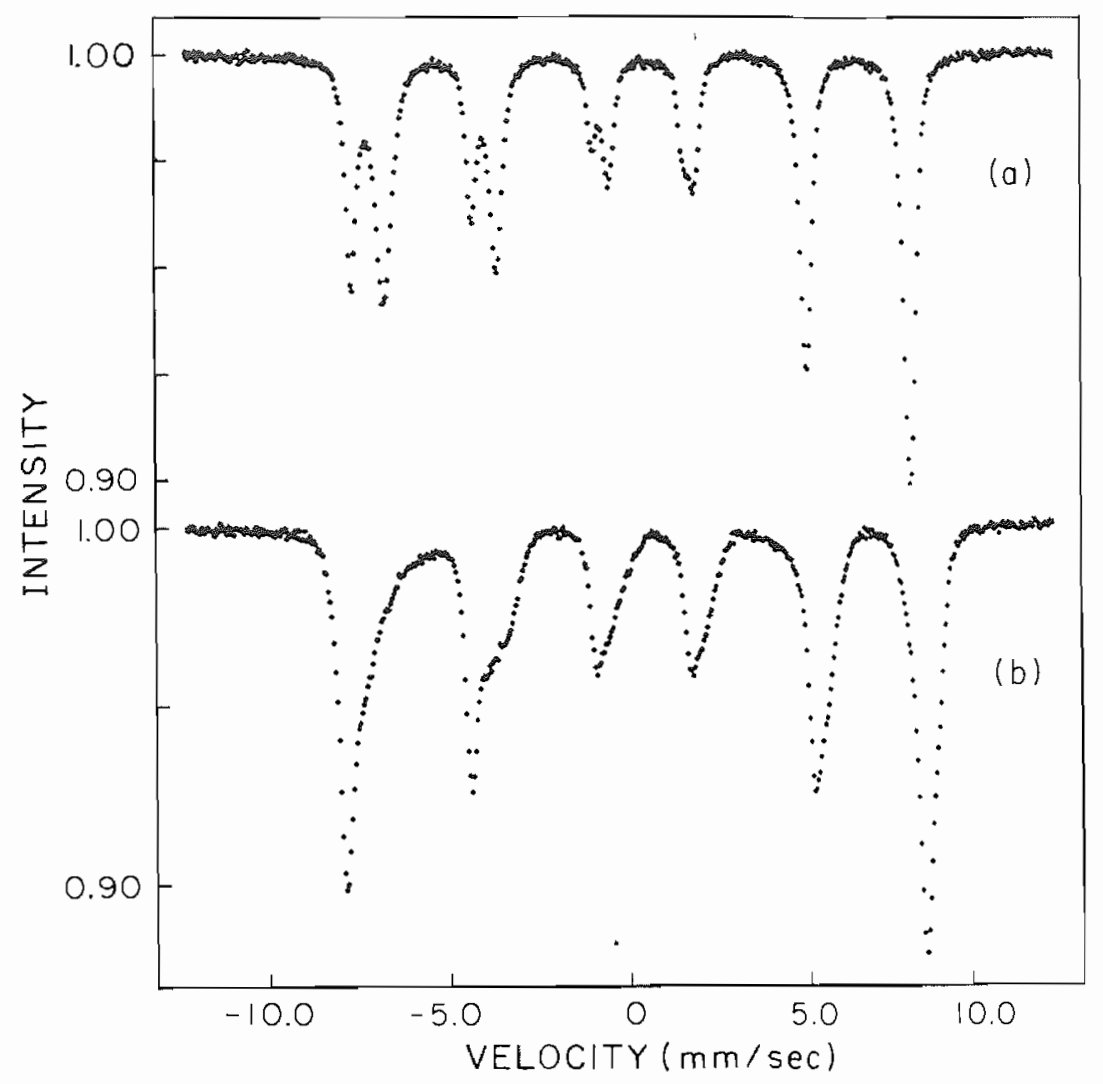

Figure 5. Mössbauer spectrum of $\mathrm{Fe}_{3} \mathrm{O}_{4}$ at (a) room temperature and (b) $80^{\circ} \mathrm{K}$.

$10^{\circ} \mathrm{K}$. The low-temperature magnetic hyperfine field is $460 \mathrm{kOe}$ (Johnson, 1969). $\delta$-FeOOH has $\mathrm{Fe}^{3+}$ atoms in a hexagonally close-packed oxygen lattice with unequal mumbers of $\mathrm{Fe}^{3+}$ ions in different layers. Unlike the other FeOOH structures, the magnetic structure is ferrimagnetic with two overlapping Mössbauer subspectra at $80^{\circ} \mathrm{K}$ with magnetic hy. perfine fields of 505 and $525 \mathrm{kOe}$ (Dezsi et al., 1967).

$5 \mathrm{Fe}_{2} \mathrm{O}_{3} \cdot 9 \mathrm{H}_{2} \mathrm{O}$, ferrihydrite, is a naturally occurring hydrous iron oxide which is thought to be similar to the iron core of the iron storage protein ferritin. Natural and synthetic samples exhibit varying degrees of crystallinity and corresponding variations in $\mathrm{X}$-ray diffraction patterns. It contains $\mathrm{Fe}^{3-}$ ions in octahedral sites, coordinated to $\mathrm{O}, \mathrm{OH}$, and $\mathrm{OH}_{2}$. The Mössbauer spectrum at room temperature consists of a quadrupole doublet with broad lines, indicating several slightly inequivalent iron sites. At $4.2^{\circ} \mathrm{K}$, a magnetically split spectrum with $H_{\mathrm{hf}} \simeq 500 \mathrm{kOe}$ is obtained, but again with broad lines indicating a distribution of magnetic hyperfine fields (Murad and Schwertmann, 1980).

Spectra for a naturally occurring amorphous iron oxide gel have also been obtained. This material has a composition corresponding to $\mathrm{Fe}(\mathrm{OH})_{3} \cdot 0.9 \mathrm{H}_{2} \mathrm{O}$ with octahedrally coordinated iron atoms but no long-range structural order. For $\mathrm{T}>20^{\circ} \mathrm{K}$, the spectrum consists of a quadrupole doublet. At $4.2^{\circ} \mathrm{K}$, the spectrum is split with a hyperfine field $H_{\mathrm{h}} \cong$ $460 \mathrm{kOe}$. External field measurements indicate that the material is paramagnetic for $\mathrm{T}>$ $100^{\circ} \mathrm{K}$, superparamagnetic for $10^{\circ} \mathrm{K}<\mathrm{T}<100^{\circ} \mathrm{K}$, and magnetically ordered below $10^{\circ} \mathrm{K}$ (Coey and Readman, 1973). 
TABLE I. Mössbauer Parameters at $80^{\circ} \mathrm{K}$

\begin{tabular}{|c|c|c|}
\hline Material & $\delta(\mathrm{mm} / \mathrm{sec})^{a}$ & $\Delta E_{Q}(\mathrm{~mm} / \mathrm{sec})^{b}$ \\
\hline \multicolumn{3}{|l|}{ A. magnetotacticum } \\
\hline Spectrum B & $0.47 \pm 0.03$ & $0.65=0.05$ \\
\hline Spectrum C & 1.32 & 3.17 \\
\hline Nonmagnetic cells & 0.47 & 0.68 \\
\hline Cloned, nommagnetic cells & 0.51 & 0.65 \\
\hline Ferritin & 0.47 & 0.73 \\
\hline \multicolumn{3}{|l|}{ E. coli } \\
\hline Storage material & 0.50 & 0.66 \\
\hline \multicolumn{3}{|l|}{ Molpadia intermedia } \\
\hline Dermal granules & 0.48 & 0.84 \\
\hline Ferrihydrite & 0.47 & 0.74 \\
\hline Amorphous ferric ge! ${ }^{! l}$ & 0.47 & 0.81 \\
\hline
\end{tabular}

\subsection{Biomineralization Products}

A number of iron biomineralization products have been studied by Mössbauer spectroscopy (Table I). An important class of iron biominerals occur in the cores of the iron storage proteins including ferritin, hemosiderin, and gastroferrin. These proteins are large spherical molecules, $120 \AA$ in diameter with 70 - $\AA$-diameter iron-containing cores. The iron is sequestered as a ferric oxyhydroxide of approximate composition $(\mathrm{FeOOH})_{83} \cdot \mathrm{FeO} \cdot \mathrm{PO}_{4} \mathrm{H}_{2}$ (Blaise et al., 1965).

The Mössbauer spectrum of horse spleen ferritin shows evidence of superparamagnetism for $20^{\circ} \mathrm{K}<\mathrm{T}<60^{\circ} \mathrm{K}$. Below $20^{\circ} \mathrm{K}$, the spectrum is magnetically split with $H_{\text {hf }}=500$ kOe. Above $60^{\circ} \mathrm{K}$, the spectrum is a quadrupole doublet. Between 20 and $60 \mathrm{kOe}$, the magnetically split spectrum and the quadiupole cloublet coexist with the intensities of the former and latter respectively decreasing and increasing with increasing temperature. The spectral effects in this temperature range are consistent with an average particle diameter of $70 \AA$ and an anisotropy constant of $-10^{4} \mathrm{ergs} / \mathrm{cm}^{3}$. Hemosiderin gives spectra that are very similar to those of ferritin (Fig. 6). The spectra of ferritin from the fungus Phycomyces and of bacterioferritin from Azotobacter are similar to mammalian ferritin except that the superparanagnetic behavior is observed over lower temperature ranges. If the core compositions in all ferritins are similar, we can assume that the decrease in the blocking temperatures reliect smaller paricle sizes in the plant and bacterioferritins (Oosterhuis and Spartalian, 1976).

An iron-rich storage material of as yet unknown composition has been found in E. coli and other prokaryotes, P. mirabilis and M. capricolum. The Mössbauer spectrum for $\mathrm{T}>10^{\circ} \mathrm{K}$ of the iron storage materials from $\mathrm{E}$. coli is a quadrupole doublet with parameters characteristic of high-spin Fe $e^{3 *}$. A six-line magnetic hyperfine spectrum with an effective magnetic field at the nucleus of $430 \mathrm{kOe}$ is observed at $\mathrm{T}<1^{\circ} \mathrm{K}$. Above $1^{\circ} \mathrm{K}$, the lines broaden and the splitting decreases with increasing $T$ and collapses into the quadrupole doublet at about $3.5^{\circ} \mathrm{K}$. Between 1.2 and $3.5^{\circ} \mathrm{K}$. the doublet and sextet are superposed. indicating a spread of magnetic transition temperatures. This indicates lower-energy maglietic interactions between iron atoms than in ferritin, perhaps reflecting less dense packing of the iron atoms than in ferritin (Bauminger et al., 1980). 


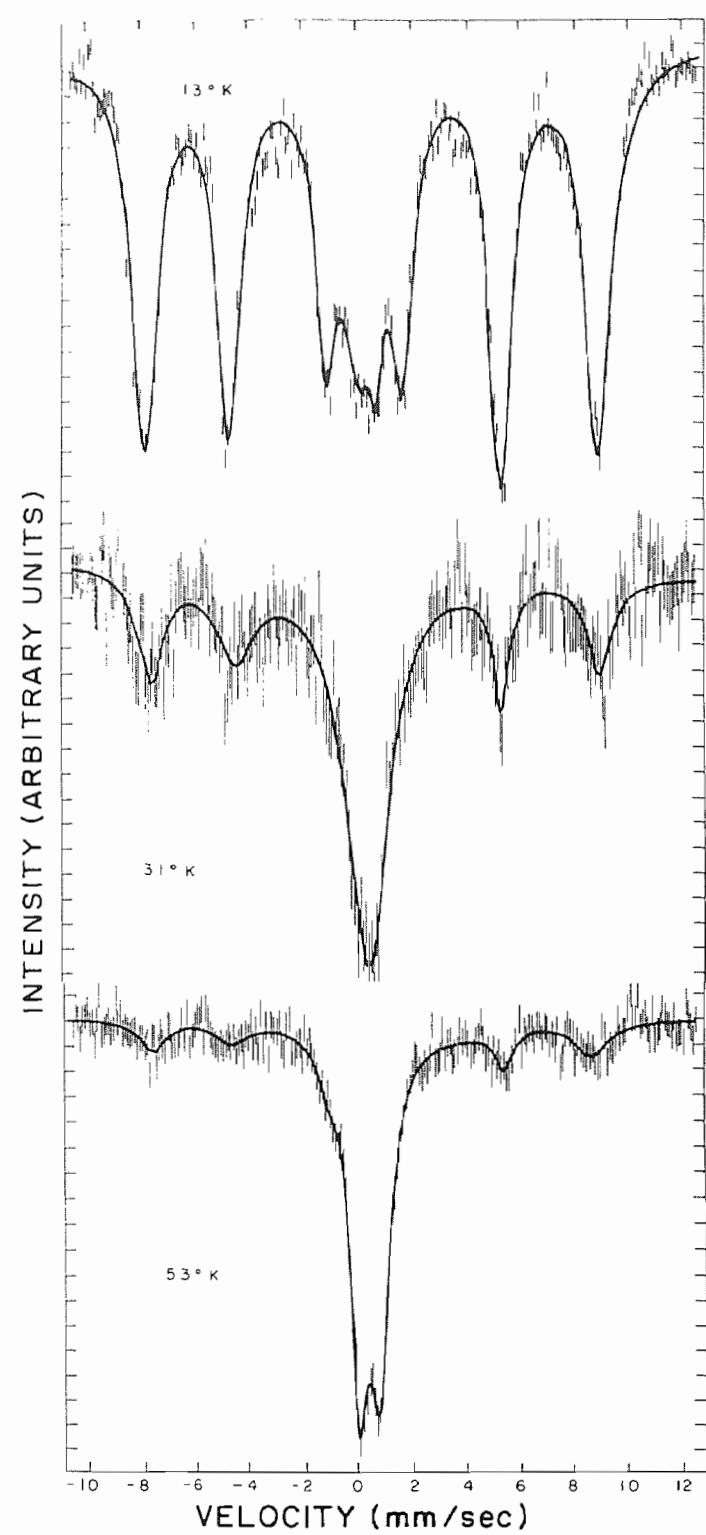

Figure 6. Mössbauer spectra of hemosiderin in heart tissue. From Kaufman et al. (1980).

Molpadia intermedia is a species of marine invertebrate that synthesizes iron- and phosphate-rich dermal granules ranging in size from 10 to $350 \mu \mathrm{m}$. These serve as strengthening agents in the connective tissues of their dermis. The granules consist of layers composed of two types of spherical to ellipsoidal subunits 0.03 to $0.24 \mu \mathrm{m}$ in diameter, separated and alternately encapsulated by organic material. One type of subunit contains water, iron, and phosphate with lesser amounts of calcium and magnesium. These deposits are X-ray amorphous and in turn consist of electron-dense subunits 90-140 $\AA$ in diameter. The iron is present in the form of hydrous ferric polymeric units similar to the iron-containing micelles of ferritin (Lowenstam and Rossman, 1975).

The Mössbauer spectrum at temperatures between 10 and $300^{\circ} \mathrm{K}$ is a broadened quadrupole doublet indicating a distribution of electric field gradients at the iron sites. Below 


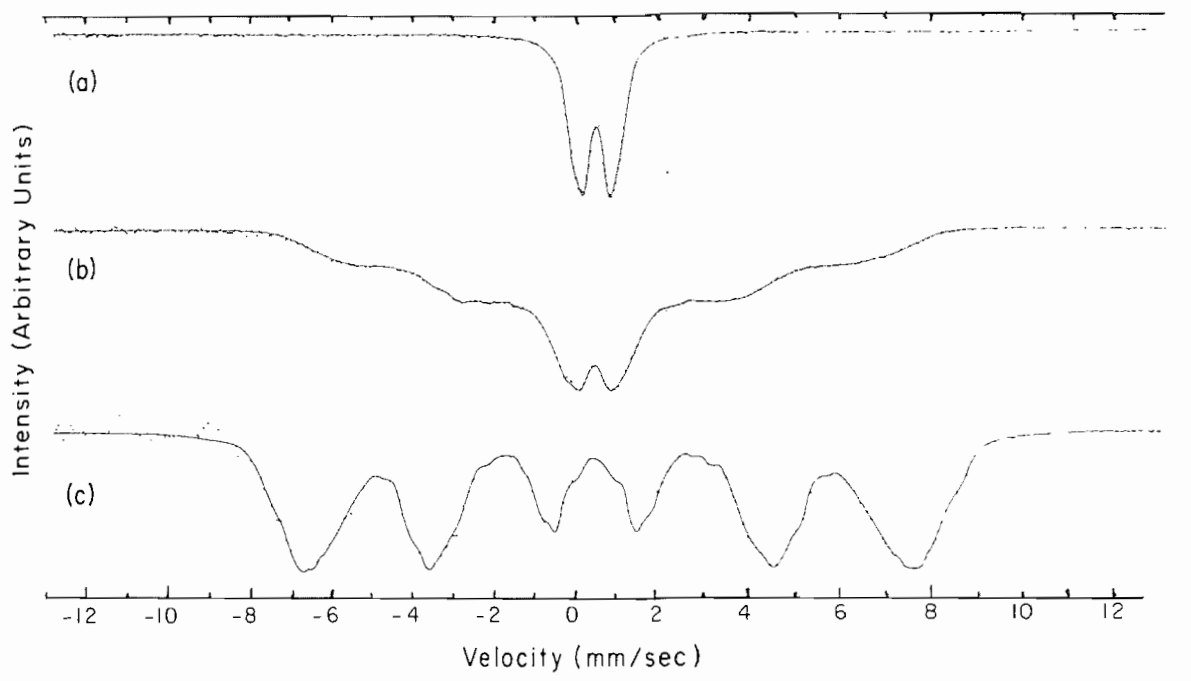

Figure 7. Mössbauer spectra of iron phosphatic dermal granules from Molpadia intermedia at (a) 20 , (b) 7.2 , and (c) $1.6^{\circ} \mathrm{K}$. From Ofer et al. (1981).

$10^{\circ} \mathrm{K}$, the spectrum broadens and magnetic hyperfine structure appears, with the effective magnetic field at the nucleus increasing with decreasing temperature. The breadth of the lines indicates a distribution of magnetic hyperfine fields. At $1.6^{\circ} \mathrm{K}$, the mode of the distribution is at $420 \mathrm{kOe}$ and moves to progressively lower fields with increasing $T$, collapsing at about $10^{\circ} \mathrm{K}$ (Fig. 7). The quadrupole doublet and the magnetically split spectra coexist from $\sim 8.0$ to $10.0^{\circ} \mathrm{K}$. The collapse of the magnetic hyperfine spectrum is indicative of a magnetic transition at about $10^{\circ} \mathrm{K}$. A longitudinal magnetic field of $80 \mathrm{kOe}$ at $4.2^{\circ} \mathrm{K}$ broadens the lines without substantially changing the line positions or relative intensities. This indicates antiferromagnetic ordering of the iron atoms in the granules (Ofer et al., 1981).

\section{Application of Mössbauer Spectroscopy to Magnetotactic Bacteria}

\subsection{Magnetotaxis in Bacteria}

Magnetotactic bacteria are various species of aquatic microorganisms that orient and swim along magnetic field lines (Blakemore, 1975, 1982; Moench and Konetzka, 1978; Blakemore and Frankel, 1981). All magnetotactic cells examined to date by electron microscopy contain iron-rich, electron-opaque particles (Balkwill et al., 1980; Towe and Moench, 1981j. In several species of magnetotactic bacteria, and possibly all, the particles consist of magnetite, $\mathrm{Fe}_{3} \mathrm{O}_{4}$ (Frankel et al., 1979). Cuboidal, rectangular, parallelepiped, and arrowhead-shaped particles occur in different species with typical dimensions of 400 to $1200 \AA$. This places the $\mathrm{Fe}_{3} \mathrm{O}_{4}$ particles in the single-magnetic-domain size range. In most species, the particles are arranged in chains, which impart a magnetic moment to the cell, parallel to the axis of motility. The moment is sufficiently large that the bacterium is oriented in the geomagnetic field at room temperature as it swims, i.e., the chain of $\mathrm{Fe}_{3} \mathrm{O}_{4}$ particles functions as a biomagnetic compass (Frankel and Blakemore, 1980). The organism thus propels itself along the geomagnetic field lines. The direction of migration 
depends on the orientation of the biomagnetic compass. Those with north-seeking jole forward migrate north along the field lines. Those with south-seeking pole forward migrale south. It has been found that north-seeking bacteria predominate in the northern hemisphere while south-seeking bacteria predominate in the southern hemisphere (Blakemore et al., 1981; Kirschvink, 1980). The vertical component of the inclined geomagnetic lield selects the predominant polarity in each hemisphere by favoring those cells whose polarity causes them to be directed downward toward the sediments and away from the toxic effects of the oxygen-rich surface waters. At the geomagnetic equator where the vertical component is zero, both polarities coexist; presumably, horizontally directed notion is equally beneficial to both polarities in reducing harmful upward migration (Frankel et al., 1981; Frankel, 1982)

In the freshwater magnetotactic spirillum, Aquaspirillum magnetotacticum, iron comprises $2 \%$ or more of the cellular dry weight. Electron microscopic studies of this organism show that the $\mathrm{Fe}_{3} \mathrm{O}_{4}$ particles are cuboidal, 400-500 $\AA$ in width, and are arranged in a chain that longitudinally traverses the cell (Fig. 8). The particles are enveloped by electrontransparent and electron-dense layers; a particle and its enveloping nembrane has been termed a magnetosome (Balkwill et al., 1980).

Because A. magnetotacticum is cultured in a chemically defined medium in which iron is available as soluble ferric quinate (Blakemore et al, 1979), the presence of intracellular $\mathrm{Fe}_{3} \mathrm{O}_{4}$ implies a process of bacterial precipitation of this mineral, with control of particle size, number, and location in the cell.

In order to elucidate the $\mathrm{Fe}_{3} \mathrm{O}_{4}$ biomineralization process, we have studied cells and cell fractions, some isotopically enriched in ${ }^{57} \mathrm{Fe}$, by Mössbauer spectroscopy. Cells of a nonmagnetotactic variant that accumulated iron but did not make $\mathrm{Fe}_{3} \mathrm{O}_{4}$ and of a cloned, nonmagnetotactic strain that accumulated less iron, were also studied. The results suggest that $\mathrm{Fe}_{3} \mathrm{O}_{4}$ is precipitated by reduction of a hydrous iron oxide precursor (Franke) ef al., 1983).

\subsection{Mössbauer Spectroscopy}

Mössbauer spectra of wet packed cells enriched in ${ }^{57} \mathrm{Fe}$ at $200^{\circ} \mathrm{K}$ and at $80^{\circ} \mathrm{K}$ are shown in Figs. 9 and 10, respectively. The $200^{\circ} \mathrm{K}$ spectrum can be analyzed as a superposition of spectra corresponding to $\mathrm{Fe}_{3} \mathrm{O}_{4}$ (spectrum A), a broadened quadrupole doublet with parameters characteristic of ferric iron (spectrum B), and a weak quadrupole doublet with parameters corresponding to ferrous iron (spectrum C) (Table 1). Spectrum A is itself a superposition of subspectra corresponding to the $\mathrm{Fe}^{2+}$ and $\mathrm{Fe}^{3-}$ in octahedral sites $\left[\mathrm{A}_{2}\right]$ and the $\mathrm{Fe}^{3+}$ in tetrahedral sites in $\mathrm{Fe}_{3} \mathrm{O}_{4}\left(\mathrm{~A}_{1}\right)$.

Spectrum B is also observed in lyophilized cells and has isomer shift and quadrupole splitting parameters similar to iron in ferritin and in the mineral ferrihydrite, indicative of ferric iron with oxygen coordination. The relative intensity of $\mathrm{B}$ to $\mathrm{A}$ is somewhat variable from sample to sample, depending on growth conditions. At $80^{\circ} \mathrm{K}$, spectrum A corresponds to $\mathrm{Fe}_{3} \mathrm{O}_{4}$ below the Verwey transition (Fig. 5) and the parameters of spectrum $B$ and the relative intensity of $B$ to $A$ are relatively unchanged compared to the spectrum at $250^{\circ} \mathrm{K}$. Between 80 and $4.2^{\circ} \mathrm{K}$, however, the intensity of $\mathrm{B}$ decreases with decreasing temperature so that at $4.2^{\circ} \mathrm{K}$, only a residual doublet remains. A similar temperature dependence for spectrum $\mathrm{B}$ is also obtained in lyophilized cells.

The isomer shift and quadrupole splitting parameters of spectrum $C$ correspond to high-spin ferrous iron in coordination with oxygen or nitrogen. This spectrum was not observed with lyophilized cells, possibly as a result of oxidation during sample preparation. Wet packed cells kept unfrozen under anaerobic conditions contain increased amounts of material responsible for spectrum $\mathrm{C}$ and correspondingly less material with 


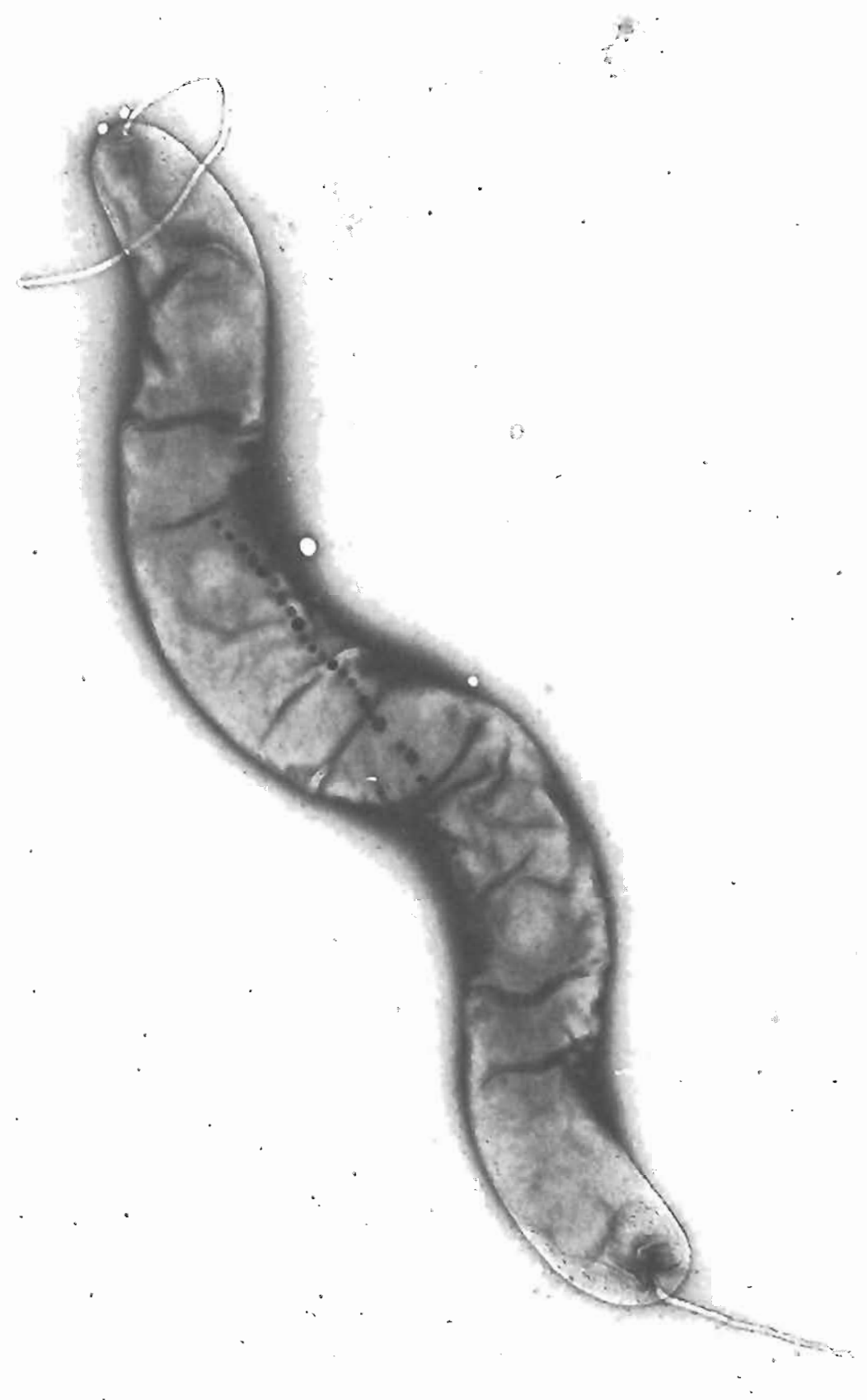

Figure 8. Electron micrograph of magnetosomes in A. magnetotacticum. The bacterium is approximately $3 \mu \mathrm{m}$ long. 


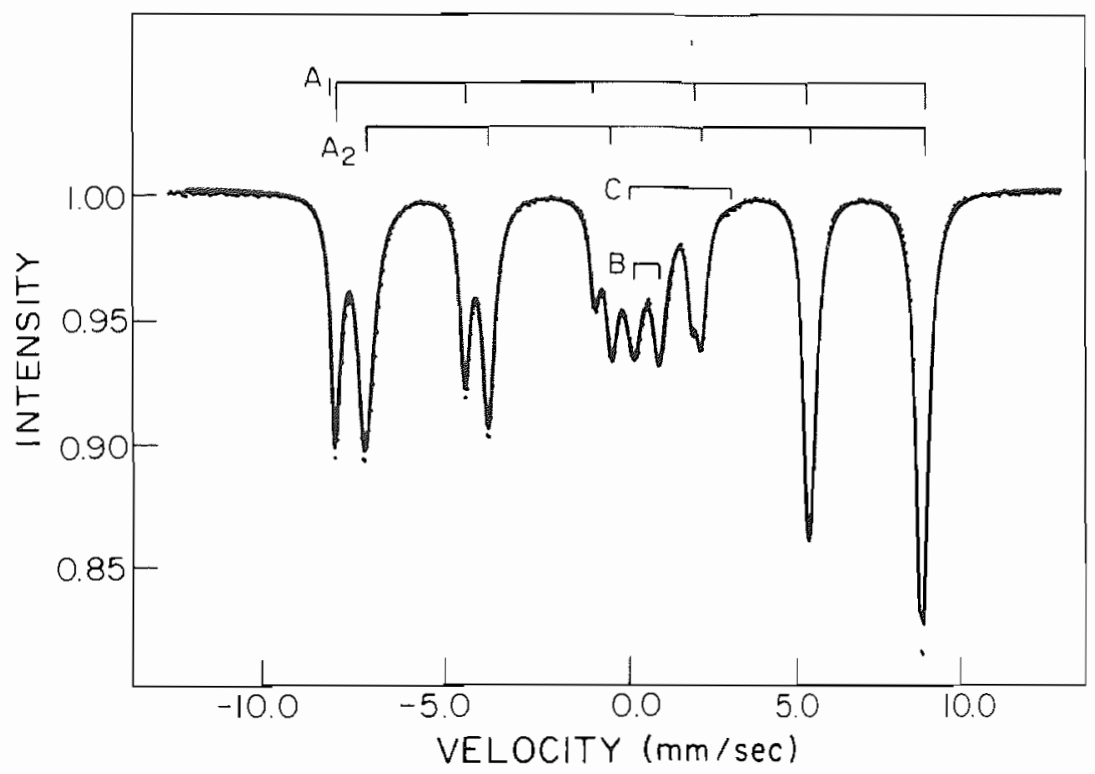

Figure 9. Mössbauer spectrum of A. magnetotacticum wet packed cells at $200^{\circ} \mathrm{K}$

spectral characteristics B. Thawing and aeration of these frozen cells result in increases in B spectral lines and concomitant decreases in $\mathrm{C}$ spectral lines. This indicates that the iron atoms responsible for spectrum $\mathrm{C}$ came from reduction of the iron atoms giving spectrum B. Unlike that of spectrum B, the intensity of spectrum $C$ does not decrease between 80 and $4.2^{\circ} \mathrm{K}$.

The decrease in the intensity of spectrum $\mathrm{B}$ between 80 and $4.2^{\circ} \mathrm{K}$ can be explained as the onset of magnetic hyperfine interactions at low temperature resulting in a concomitant decrease in the intensity of the central absorption doublet. This phenomenon has been observed with Mössbauer spectroscopy of ferritin and hemosiderin (Fig. 6). However,

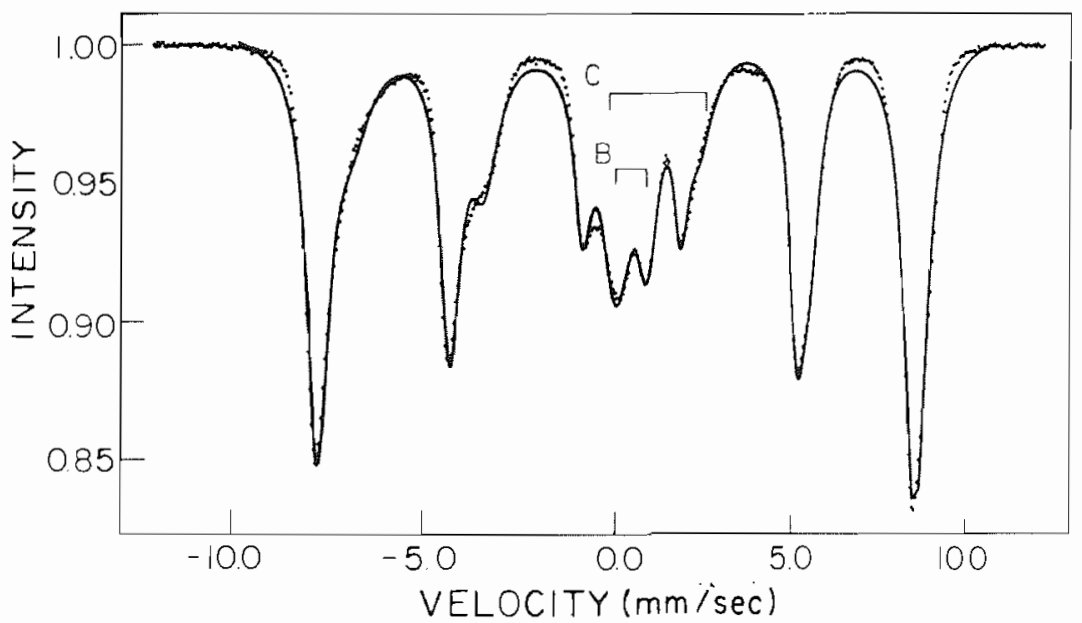

Figure 10. Mössbauer spectrum of A magnetotacticum wet packed cells at $80^{\circ} \mathrm{K}$. 


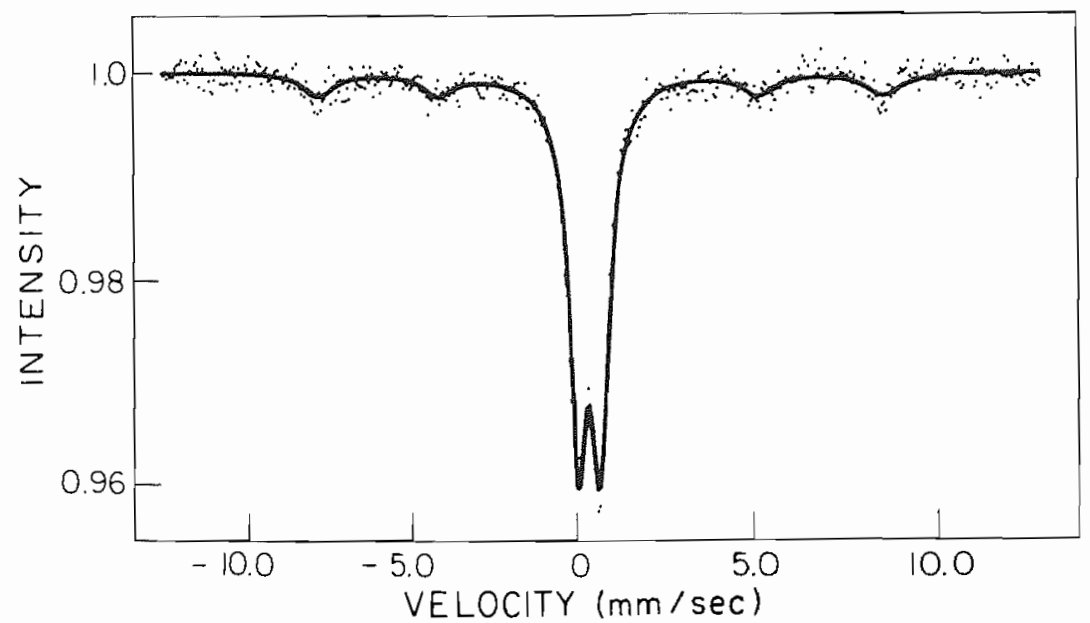

Figure 11. Mössbauer spectrum of nonmagnetotactic cells at $80^{\circ} \mathrm{K}$. Some residual $\mathrm{Fe}_{3} \mathrm{O}_{4}$ is present in the sample.

in the present case, the magnetic hyperfine lines are obscured by the magnetite spectra] lines $\left(A_{1}\right.$ and $\left.A_{2}\right)$. To further resolve the nature of the material responsible for spectrum $B$, we studied the temperature-dependent Mössbauer spectra of nonmagnetotactic cells which lacked the interfering magnetite.

For $T \geq 80^{\circ} \mathrm{K}$, the spectrum of lyophilized nonmagnetotactic cells (Fig. 11) consists primarily of the quadrupole doublet characteristic of ferric iron as denoted by spectrum $\mathrm{B}$ in Figs. 9 and 10. In addition, a very-low-intensity spectrum due to $\mathrm{Fe}_{3} \mathrm{O}_{4}$ (spectral lines $A_{1}+A_{2}$ in Fig. 9) is observed. These latter spectral lines might be due to a small fraction of magnetotactic cells in the sample or trace amounts of magnetite possibly present in the nonmagnetotactic cells. Below $80^{\circ} \mathrm{K}$, the intensity of the quadrupole doublet decreased with decreasing temperature while the intensity of a six-line spectrum flanking the doublet increased. At $4.2^{\circ} \mathrm{K}$, the spectrum (Fig. 12) consists primarily of the six broadened magnetic hyperfine lines, with a small residual doublet in the center. The $\mathrm{Fe}_{3} \mathrm{O}_{4}$ spectrum was then obscured by the six-line spectrum. Application of a longitudinal magnetic field of $60 \mathrm{kOe}$ produced broadening of the six-line spectrum but with no appreciable shifts in the line positions and no decreases in any line intersities.

These spectral characteristics are indicative of small particles of hydrous ferric oxide with antiferromagnetic exchange interactions similar to those of the ferrihydrite within ferritin micelles. If we use values of $K$ and $f_{0}$ appropriate to ferritin, the experimental results indicate that hydrous ferric oxide particles in the nonmagnetotactic cells are of the order of $100 \AA$ in diameter, or less. Unlike ferritin or ferrihydrite, however, there is a residual quadrupole doublet in the $4.2^{\circ} \mathrm{K}$ spectra of magnetotactic and nonmagnetotactic cells. The intensity of this residual doublet varies somewhat from sample to sample, but its presence suggests another high-spin ferric iron material with high-temperature spectral characteristics similar to those of ferrihydrite, but with iron atoms less densely packed so that magnetic exchange interactions between them are weaker and the spectrum is not magnetically split at $4.2^{\circ} \mathrm{K}$. This latter material is more easily studied in a cloned, nonmagnetotactic strain of $A$. magnetotacticum that accumulates less iron.

The Mössbauer spectrum of wet packed cells of the cloned, nonmagnetotactic strain consists of a quadrupole absorption doublet for $T \geq 4.2^{\circ} \mathrm{K}$ (Fig. 13). The spectral parameters obtained at $80^{\circ} \mathrm{K}$ were similar to those of spectrum $\mathrm{B}$ in magnetotactic cells (Table I), 


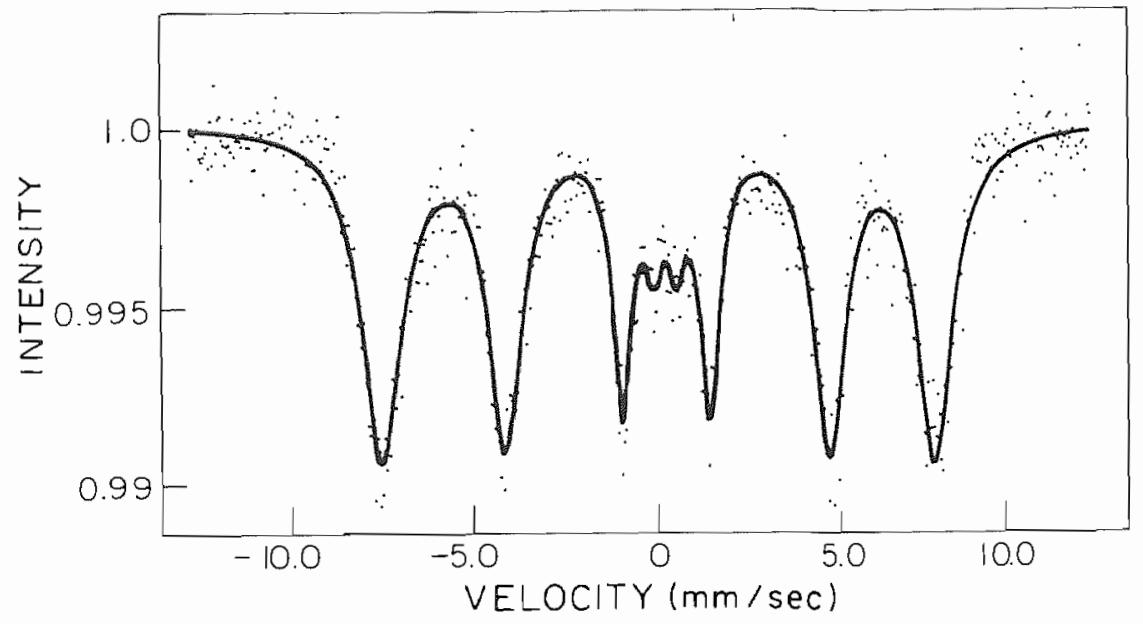

Figure 12. Mössbauer spectrum of nonmagnelotactic cells at $4.2^{\circ} \mathrm{K}$.

indicating the presence of a high-spin ferric iron material. Application of an external 60 kOe magnetic field at $4.2^{\circ} \mathrm{K}$ results in spectra with a broad distribution of hyperfine fields. These spectral characteristics indicate the presence of high-spin $\mathrm{Fe}^{3+}$ in a hydrous oxide with magnetic exchange interactions of the order of $2-3^{\circ} \mathrm{K}$. that is, where the iron atoms are less densely packed than in ferrihydrite. This material has similar spectral characteristics to the iron storage material in E. coli (Bauminger et al., 1980).

When the wet packed cells were held above $275^{\circ} \mathrm{K}$ in an anaerobic environment, a ferrous spectrum similar to spectrum $C$ appeared, in addition to the ferric iron doublet. This indicates that the hydrous ferric oxide in cells of this strain can be reduced to ferrous iron as with cells of the other strains.

Diffusive motions of the magnetosomes in A. magnetotacticum have been observed in the Mössbauer spectrum of whole cells above $275^{\circ} \mathrm{K}$. The temperature dependence of

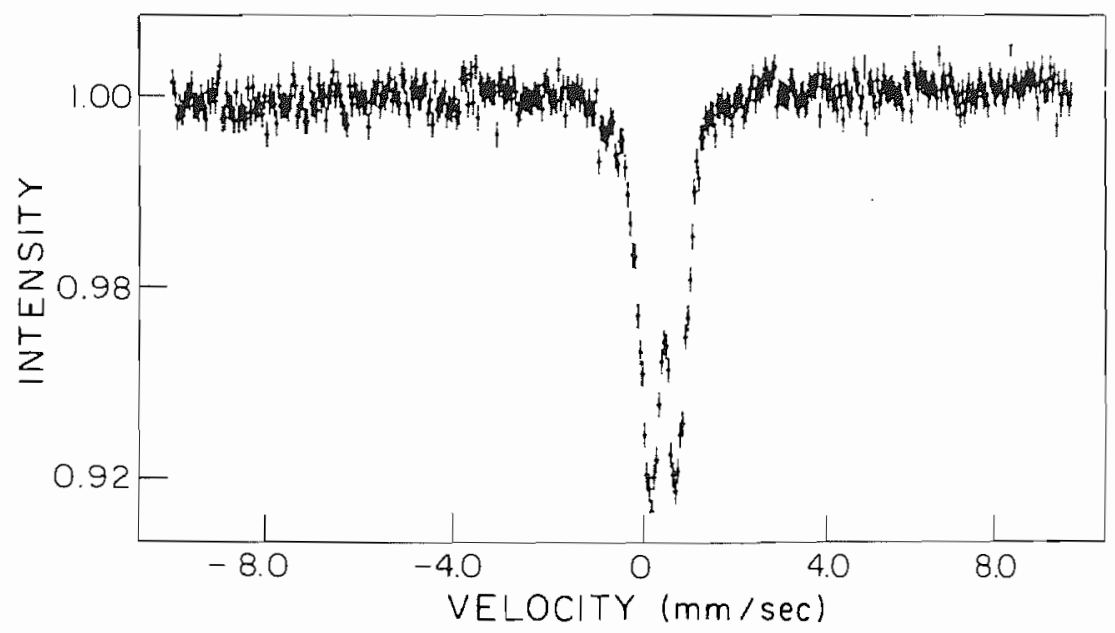

Figure 13. Mössbauer spectrum of cloned, nonmagnetotactic strain of A. magnetolacticum at $4.2^{\circ} \mathrm{K}$. 
the ferrihydrite spectrum is consistenl with the association of the ferrihydrite with the magnetosomes. Ferrous iron in the cells appears to be associated with the peptidoglycan of the cell wall (Ofer et al., 1984).

The foregoing results suggest that $A$. magnetotacticum precipitates $\mathrm{Fe}_{3} \mathrm{O}_{4}$ in the sequence [1] $\mathrm{Fe}^{\text {i. }+}$ quinate $\rightarrow$ (2) low-density hydrous ferric oxide $\rightarrow$ (3) high-density hydrous ferric oxide (ferrihydrite) $\rightarrow(4) \mathrm{Fe}_{3} \mathrm{O}_{4}$ with $\mathrm{Fe}^{2+}$ appearing as a transient between (1) and (2). Because ferrihydrite contains ferric iron only, [3] $\rightarrow$ (4) implies reduction of one-third of the iron atoms. The cleposition of ferrihydrite and subsequent reductions and precipitation of $\mathrm{Fe}_{3} \mathrm{O}_{4}$ occur in the magnetosome envelope. High resolution transmission electron microscopy gives evidence for an amorphous (ferrihydrite) phase as well as single crystal $\mathrm{Fe}_{3} \mathrm{O}_{4}$ with well defined morphology and orientation in the magnetosomes [Mann et al., 1984).

Reduction of a ferrihydrite precursor to $\mathrm{Fe}_{3} \mathrm{O}_{4}$ occurs in the marine chiton, a mollusc of the order Polypiacophora. In this organism, the radular teeth undergo a sequential mineralization process that results in a surface coating of $\mathrm{Fe}_{3} \mathrm{O}_{4}$. Iron is transported to the superior epithelial cells of the radula in the storage protein ferritin. Then, iron is transferred to a preformed organic matrix on the tooth surface as ferrihydrite. Finally, the ferrihydrite is reduced to $\mathrm{Fe}_{3} \mathrm{O}_{4}$. The resulting $\mathrm{Fe}_{3} \mathrm{O}_{4}$ particles have dimensions of the order of $0.1 \mathrm{\mu m}$ (Towe and Lowenstam, 1967; Kirschvink and Lowenstam, 1979).

Cells containing hydrous iron oxide granules have been found in the bands around each abdominal segment in honeybees (Kuterbach et al., 1982). Honeybees are sensitive to the geomagnetic field and are known to have $\mathrm{Fe}_{3} \mathrm{O}_{4}$ in their abdomens (Gould et al., 1978). Scme of the hydrous iron oxide in the granules could serve as a precursor to $\mathrm{Fe}_{3} \mathrm{O}_{1}$ formation.

Thus, $\mathrm{Fe}_{3} \mathrm{O}_{4}$ precipitation might follow similar pathways in a wide variety of organisms. In the bacteria, however, we have the best opportunity to elucidate the biochemical details of the process and its comnection to overall cellular metabolism.

ACKNowl.EDGMANTS. R.B.F. and G.C.P. were partially supported by the Office of Naval Research. The Trancis Bitter National Magnet Laboratory is supported by the National Science Foundation. R.P.B. was supported by the Office of Naval Research and the National Science Foundation.

\section{References}

Amstrong, R. I., Morrish, A. H., and Sawatzky, G. A, 1966, Mossbauer study of ferric ions in the tetrahedral and octahedral sites of a spinel. Phys. Lett 23:414-416.

Balkwill, D. L., Maratea, D., and Blakemore, R. P., 1980, Lltrastructure of a magnetotactic spirillum. J. Bacleriol. 141:1399-1408.

Bancroft, G. M., 1973, Mössbater Spectroscopy: An Introduction for Inorgunic Chemists and Geochemists. McGraw-Hili, New York.

Banerjee, S. K., O'Reilly, W., and Johnson, C. E. 1967, Mössbauer effect measurenents in FeTi spinels with local disorder, f. Appl. Plys. 38:1289-1291.

Bauminger, E. R., Cohen, S. G., Dickson, D. P. E., Levy. A., Ofer, S., and Yariv, ]. 1980, Móssbauer spectroscopy of E. coli and its iron storage protein, Biochin. Biophys. Acta 623:237-242.

Blaise, A., Chappert, J., and Givadet. J, L.. 1965, Observation par mesures magnétiques et effet Mössbauer d'un antiferromagnétisme de grains fins dans la ferritine, C. R. Acad. Sci. 261:2310-2313.

Blakemore, R. P., 1975, Magnelotactic bacteria, Science 190:377-379.

Blakemore, R. P., 1982, Magnetotactic bacteria, Annu. Rev. Microbiol. 36:217-238.

Blakemore, R. P., and Frankel, R. B., 1981, Magnetic navigation in bacteria, Sci. An. 245(6):58-65.

Blakemore, R. P., Maratea, D., and Wolfe, R. S. 1979. 1solation and pure culture of a fresh water magnetic spirillum in chemically deíined medium. J. Bacleriol 140:720-729. 
Blakemore, R. P., Frankel, R. B., and Kalmijn, A. J., 1981, South-seeking magnetotaclic bacteria in the southern hemisphere, Nature 286:384-385.

Chappert, J., Teillet, J, and Varret, F., 1979, Recent developments in high field Mössbauer spectroscopy, J. Magn. Magn. Mater. 11:200-207.

Coey, J. M. D., and Readman, P. W., 1973, Characterization and magnetic properties of a natural ferric gel, Earth Planet. Sci. Lett. 21:45-51.

Cohen, R. L. (ed.), 1976, Applications of Mössbauer Spectroscopy, Volume I, Academic Press, New York.

Cohen, R. L. (ed.), 1981, Applications of Mössbaver Spectroscopy, Volnme II, Academic Press, New York.

Dezsi, I., Keszthelyi, L., Kulgawczuk, D., Molnár, B., and Eissa, N. A., 1967, Mössbauers study of $\beta$ and 8-FeOOH, Phys. Status Solidi 22:617-629.

Forsyth, J. B., Hedley, I. G., and Johnson, C. E., 1968, The magnetic structure and hyperfine field of goethite $(\delta-\mathrm{FeOOH})$, J. Phys. C (Ser. 2) 2:179-188.

Frankel, R. B., 1982, Magnetotactic bacteria, Comments Mol. Cell. Biophys. 1:293-310.

Frankel, R. B., and Blakemore, R. P., 1980, Navigational compass in magnetic bacteria, J. Magn. Magn. Mater. 15-18:1562-1564.

Frankel, R. B., Blakemore, R. P., and Wolfe, R. S., 1979, Magnetite in freshwater magnetotactic bacteria, Science 203:1355-1356.

Frankel, R. B., Blakemore, R. P., Torres de Araujo, F. F., Esquivel, D. M. S., and Danon, j., 1981, Magnetotactic bacteria at the geomagnetic equator, Science 212:1269-1270.

Frankel, R. B.. Papaefthymiou, G. C., Blakemore, R. P., and O'Brien, W. D., 1983, $\mathrm{Fe}_{3} \mathrm{O}_{4}$ precipitation in magnetotactic bacteria, Biochim. Biophys. Acta 763:147-159.

Freeman, A. J., and Frankel, R. B., 1967, Hyperfine Interactions, Academic Press, New York.

Gould, J. L., Krischvink, J. L., and Deffeyes, K. S., 1978, Bees have magnetic remanence, Science 201:1026-1028.

Greenwood, N. N., and Gibb, T. C., 1971, Mössbauer Spectroscopy , Chapman \& Hall, London.

Hargrove, R. S., and Kundig, W., 1970, Mössbauer measurements of magnetite below the Verwey transition, Solid State Commun. 8:303-308.

Johnson, C. E., 1969, Antiferromagnetism of $\gamma$-FeOOH: A Mössbauer effect study, ]. Phys. C (Ser. 2) 2:1996-2002.

Kaufman, K. S., Papaefthymiou, G. C., Frankel, R. B., and Rosenthal, A., 1980, Nature of iron deposits on the cardiac walls in $\beta$-thalassemia by Mössbauer spectroscopy. Biochim. Biophys. Acta 629:522-529.

Kirschvink, J. L., 1980, South-seeking magnetic bacteria, J. Exp. Biol. 86:345-347.

Kirschvink, J. L., and Lowenstam, H. A., 1979, Mineralization and magnetization of chiton Leth: Paleomagnetic, sedimentologic and biologic implications of organic magnetite, Earth Plonet. Sci. Lett. 44:193-204.

Kuterbach, D. A., Walcott, B., Reeder, R. J., and Frankel, R. B., 1982, Iron-containing cells in the honeybee (Apis mellifera), Science 218:695-697.

Lowenstam, H. A., and Rossman, G. R., 1975, Amorphous, hydrous, ferric phosphatic dermal granules in Molpadia (Holothuroidea): Physical and chemical characterization and ecological implications of the bioinorganic fraction, Chem. Geol. 15:15-51.

Mann, S., Frankel, R. B., and Blakemore, R. P., 1984, Structure, morphology and crystal growth of bacterial magnetite, Nature 310:405-407.

McNabb, T. K., Fox, R. A., and Boyle, A. J. F., 1968, Some magnetic properties of magnetite $\left(\mathrm{Fe}_{3} \mathrm{O}_{4}\right)$ microcrystals, J. Appl. Phys. 39:5703-5711.

Moench, T. T., and Konetzka, W. A., 1978, A novel method for the isolation and study of magnetotactic bacterium, Arch. Microbiol. 119:203-212.

Murad, E., and Schwertmann, U., 1980, The Mössbauer spectrum of ferrihydrite and its relations to those of other iron oxides, Am. Mineral. 65:1044-1049.

Ofer, S., Nowik, I., Bauminger, E. R., Papaefthymiou, G. C., Frankel, R. B., and Blakemore, R. P., 1984, Magnetosome dynamics in magnetotactic bacteria, Biophys. J. 46:57-64.

Ofer, S., Papaefthymiou, G. C., Frankel, R. B., and Lowenstam, H. A., 1981, Mössbauer spectroscopy of iron-containing dermal granules from Molpadia intermedia, Biochin. Biophys. Acta 676:199204. 
Oosterhuis, W. T., and Spartalian, K., 1976, Biological iron transport and storage compounds, in: Applications of Mössbauer Spectroscopy, Volume I (R. L. Cohen, ed.), Academic Press, New York, pp. 141-170.

Towe, K. M., and Moench, T. T., 1981, Electron-optical characterization of bacterial magnetite, Earth Planet. Sci. Lett. 52:213-220.

van der Woude, F., 1966, Mössbauer effect in $\alpha-\mathrm{Fe}_{2} \mathrm{O}_{3}$, Phys. Status Solid. 17:417-432. 